\title{
DA CRISE DA PÓS-HEGEMONIA AO IMPACTO DA COVID-19. O IMPASSE DO REGIONALISMO LATINO-AMERICANO ${ }^{1}$
}

José BRICEÑO-RUIZ²

RESUMO: Neste artigo analisa-se o complexo processo que o regionalismo latinoamericano tem experimentado nas duas décadas de século XXI e seu impasse atual. Na primeira parte se discute a era do regionalismo pós-hegemônico e suas limitaçóes. A segunda parte contempla a chegada dos governos conservadores e seu impacto na estratégia regionalista, especialmente na América do Sul. Por fim, se examina a resposta dos blocos latino-americanos à pandemia da Covid-19.

PALAVRAS-CHAVE: América Latina. Regionalismo. Impasse. Crise. Covid-19.

\section{FROM THE POST-HEGEMONY CRISIS TO THE IMPACT OF COVID-19. THE IMPASS OF LATIN AMERICAN REGIONALISM}

ABSTRACT: This article analyzes the complex process that Latin American regionalism has experienced in the two decades of the 21st century and its current impasse. The first part of the paper discusses the era of post-hegemonic regionalism and its limitations. The second part contemplates the arrival of conservative governments and their impact on regionalist strategy, especially in South America. Finally, the response of the Latin American blocs to the Covid-19 pandemic is examined.

KEYWORDS: Latin America. Regionalism. Impasse. Crisis. Covid-19.

\footnotetext{
1 Este trabalho foi apoiado pelo projeto UNAM-PAPIIT IA300320 "Regionalismo latino-americano: crise e resiliência".

2 Universidad Nacional Autónoma de México, Cidade do México - México. Profesor-Investigador. Orcid: 00000003-2710-4435. bricenoruiz@hotmail.com.
} 


\section{Introdução}

Entre 2003 e 2015, o regionalismo latino-americano transitou um ciclo que foi descrito como pós-liberal ou pós-hegemônico. Como resultado da ascensão ao poder de governos de esquerda, esse ciclo regionalista representou uma ruptura com o modelo econômico e com a agenda promovida na última década do século 20, na era do regionalismo aberto. Nem todos os países latino-americanos aderiram a essa onda pós-hegemônica. Assim, apesar de passar por um período complicado depois da saída da Venezuela em 2006, a Comunidade Andina (CAN) manteve suas políticas regionais sem grandes mudanças. Um caso semelhante é o Sistema de Integração Centro-Americano (SICA), que deu continuidade ao modelo de integração e cooperação adotado na década de 1990. No entanto, novas iniciativas surgiram, como a Alternativa Bolivariana para as Américas (ALBA), anunciada por Hugo Chávez em 2001 e formalizada em um encontro em Havana com Fidel Castro em dezembro 2004. A ALBA mais tarde seria chamada Aliança Bolivariana para os Povos da América. Em 2008, foi criada a União de Naçóes Sul-Americanas (UNASUL), esquema regional que deu continuidade a iniciativas brasileiras como a Área de Livre Comércio da Sul-Americana (ALCSA) (1994) e a Comunidade Sul-Americana de Naçóes (CASA) (2000). Igualmente, em dezembro de 2011 foi criada a Comunidade de Estados da América Latina e do Caribe (CELAC), iniciativa resultante da ação de Felipe Calderón e Luiz Inácio Lula da Silva. O Mercado Comum do Sul (Mercosul), bloco regional estabelecido em 1991, passou por uma série de mudanças durante a era pós-hegemônica, em particular devido à decisão de fortalecer suas dimensóes política, econômica e social. Essas iniciativas fizeram parte de um período que é descrito neste artigo como pós-hegemônico.

O regionalismo pós-hegemônico entra em crise a partir de 2015 com a chegada ao poder de governos conservadores em Argentina e Brasil, a crise na Venezuela e a mudança política em Equador em 2017. Os governos conservadores revisaram os processos regionais para enfraquecer suas dimensóes políticas, sociais e produtivas e voltar a uma estratégia centrada no livre comércio e na firma de acordos com países desenvolvidos. Contudo, esta estratégia foi desenvolvida em um contexto internacional dominado pelo nacionalismo econômico, especialmente depois da vitória de Donald Trump nos Estados Unidos. Além disso, não houve a implementação políticas para superar as limitaçôes internas dos processos regionais. Esta situação agrava-se com a chegada da pandemia da Covid-19, levando ao regionalismo latino-americano a uma situação de impasse. 
Neste artigo analisa-se este complexo processo que o regionalismo latino-americano tem experimentado nas duas décadas de século XXI e seu impasse atual. Na primeira parte se discute a era do regionalismo pós-hegemônico e suas limitaçóes. A segunda parte contempla a chegada dos governos conservadores e seu impacto na estratégia regionalista, especialmente na América do Sul. Por fim, se examina a resposta dos blocos latino-americanos à pandemia da Covid-19.

\section{O regionalismo pós-hegemônico}

O uso da categoria pós-hegemonia foi utilizado para explicar processos regionais por especialistas em diversas partes do mundo (VÄYRYNEN, 1997; MOLCHANOV; MOLCHANOVA, 2010; TELÒ, 2011), mas, sem dúvida, sua aplicação ao regionalismo latino-americano foi feita inicialmente por Pia Riggirozzi e Diana Tussie (2012). No entanto, não está muito claro qual conceito de hegemonia esses autores utilizam para construir sua noção de pós-hegemonia. Às vezes, a pós-hegemonia se refere ao fim da hegemonia dos Estados Unidos como promotores do regionalismo no continente a partir da iniciativa da Área de Livre Comércio das Américas (ALCA). Nesse caso, a pós-hegemonia foi entendida no marco da teoria da estabilidade hegemônica no sentido de que não existia mais um hegemon (os Estados Unidos) que promovesse o regionalismo continental. Outras vezes, o pós-hegemônico significa o fim da hegemonia do neoliberalismo como fonte inspiradora de processos regionais (RIGGIROZZI; TUSSIE, 2012).

O regionalismo na América Latina entre 2013 e 2015 foi pós-hegemônico não porque os Estados Unidos deixaram de ser promotores de iniciativas de integração ou cooperação. Na verdade, o colapso da ALCA na Cúpula das Américas de Mar del Plata em 2005 não significou o fim do ativismo estadunidense na promoção de iniciativas de integração econômica que acabaram influenciando processos regionais específicos.

Os Tratados Bilaterais de Livre Comércio (TLC) que os Estados Unidos assinaram com países andinos como Chile, Colômbia e Peru possibilitaram a estandardização da legislação em aspectos como acesso a mercados, propriedade intelectual, serviços e compras governamentais. Essas regras eram semelhantes às acordadas em 1994 no Tratado de Livre Comércio da América do Norte (Nafta), do qual o México era parte. Esses 4 países decidiram estabelecer Aliança do Pacífico em 2011, uma iniciativa de integração que segue o modelo que os Estados Unidos defendem desde a criação do Nafta. 
Não se alega que a Aliança é uma invenção dos Estados Unidos, mas sim que os TLC que seus países-membros assinaram com Washington sem dúvida influenciaram seu modelo. Essa influência também existe na América Central, uma vez que os países do SICA (Costa Rica, El Salvador, Guatemala, Honduras e Nicarágua), e a República Dominicana, assinaram em 2003 um TLC com os Estados Unidos chamado CAFTA+DR (Acordo de Livre Comércio da América Central - Dominicano República). Esse acordo estabelece regulaçóes respeito aos temas já mencionados que levou a sua estandardização em todos os países do SICA, incluindo a Nicarágua sandinista liderada por Daniel Ortega. A República Dominicana ingressou como membro pleno do SICA em 2013. Isso confirma que o papel dos Estados Unidos como promotor do regionalismo náo tem desaparecido.

Portanto, a pós-hegemonia como o fim da existência de um país que promove uma ordem regional, nunca desapareceu entre 2003 e 2015 . E certo de que o Mercosul, Bolívia, Equador e Venezuela tem se distanciado, embora em formas e intensidades diferentes, dos Estados Unidos.

A pós-hegemonia pode ser entendida a partir de uma noção gramsciana-coxiana (BRICEÑO RUIZ, 2016). Nesse caso, hegemonia se refere aos valores e narrativas que são considerados válidos para uma sociedade. Nesse sentido, na década de 1990 existia praticamente uma única narrativa respeito ao regionalismo e integração econômica, ambos eram mecanismos avançar a reforma estrutural aplicada pelos governos da época, em particular com o objetivo de alcançar a inserção dos países da região na economia mundial.

Todos os processos existentes naquela década, o SICA, a CAN, o Mercosul ou o desaparecido Grupo dos Três (G-3) tiveram por base essa narrativa sobre regionalismo e integração econômica. Todos eles reivindicaram um regionalismo aberto. Isso muda no período de 2003 a 2015 quando deixou de existir uma narrativa única com respeito aos processos regionais. $\mathrm{O}$ regionalismo aberto nunca desapareceu, pois nem a CAN nem o SICA modificaram seu modelo econômico. Foi mesmo reforçado a partir de 2011 com a criação da Aliança do Pacífico. Porém, ao lado dessas narrativas "neoliberais", surgiram outras que destacavam a dimensão política, social e produtiva do regionalismo, como a UNASUL, a ALBA, o CELAC e o "novo Mercosul". Por isso, a categoria "regionalismo pós-hegemônico" é a mais apropriada para descrever a complexa realidade das iniciativas de cooperação e integração regional entre 2003 e 2015. Algumas dessas iniciativas foram "comerciais", outras multidimensionais; alguns mantiveram o modelo da década de 1990, outros o revisaram e outros o abandonaram esse modelo. 
Antes da criação da Aliança do Pacífico em 2011, processos como a ALBA, a UNASUL, o "novo Mercosul" e a CELAC eram o foco de atenção na América Latina, tanto no âmbito político quanto acadêmico. Temas como busca da autonomia implícita na proposta do Conselho de Defesa Sul-Americano da UNASUL ou a criação do Banco do Sul como alternativa ao Fundo Monetário Internacional (FMI) proposto pela Venezuela, eram o centro dos debates. Também salientou o Programa de Infraestrutura para a Integração Regional da América do Sul (IIRSA).

$\mathrm{Na}$ dimensão política, deve ser mencionado o papel da UNASUL na solução da crise política na Bolívia em 2009 e no Equador em 2011, bem como no conflito diplomático entre Colômbia e Venezuela em 2010 (BENZI; NAREA, 2019; MIJARES; NOLTE, 2018). Outro exemplo é a ALBA, que foi apresentada como um "modelo não capitalista de integração", que impulsionou programas sociais no campo da saúde e a educaçáo e, por meio do Petrocaribe, ajudou os países da Bacia do Caribe com a venda de petróleo em condiçóes especiais, numa época em que este produto tinha um preço muito elevado nos mercados mundiais. Os países da ALBA participaram ativamente na crise em Honduras resultado do golpe contra Manuel Zelaya em 2010 (BENZI, 2017; GRATIUS; PUENTE, 2018). A CELAC, por sua vez, foi apresentada por alguns países, como a Venezuela e seus aliados da ALBA, como alternativa à Organização dos Estados Americanos (OEA) (ROJAS ARAVENA, 2012; SEGOVIA, 2013).

Assim, o chamado "novo Mercosul" foi descrito como um processo multidimensional, que deu prioridade aos aspectos não comerciais do regionalismo, fortalecendo sua dimensão social, promovendo uma estratégia de transformação produtiva e realizando açóes políticas ousadas como aprovar a entrada da Venezuela e da Bolívia como membros plenos do bloco regional (RAPOPORT; MUSACCHIO, 2006; BRICEÑO RUIZ, 2011; FERNÁNDEZ GUILLÉN, 2017). Foram os anos dourados do regionalismo pós-hegemônico.

Porém, já no mesmo ano de 2011, as forças que impulsionavam os novos esquemas regionais começaram a perder influência. Em outubro de 2010, Néstor Kirchner morreu e em janeiro de 2011 Lula entregou o poder a Dilma Rousseff. No caso do Brasil, Rousseff não daria à América do Sul a importância estratégica que tinha para Lula. Em 2012, Fernando Lugo foi demitido por meio de um processo judicial polêmico que ocorre em apenas um dia, portanto, não pode ser descrito senão como um golpe de Estado. Em 2013, faleceu Hugo Chávez, outro dos promotores das iniciativas regionais, e Nicolás Maduro, um político sem carisma ou liderança para influenciar a agenda regional assume a presidência da Venezuela. 
Além disso, a crise econômica começou em muitos países da regiáo como resultado da queda nos preços das commodities. Ficou evidente que as chamadas "políticas pós-liberais" de inclusão social ou as tentativas neo-desenvolvimentistas foram uma ilusão e a regiāo por mais de uma década não somente não havia deixado de viver por conta da exportação de bens primários, mas a sua dependência destes, tinha se incrementado. Isso foi chamado de Consenso de Commodities e neo-extrativismo (SVAMPA, 2012, 2017) Políticas macroeconômicas erradas, especialmente em matéria fiscal e cambial, levou à recessão na Argentina, Brasil e Venezuela, esta última associada a uma profunda crise política e institucional e um giro cada vez mais autoritário do governo de Maduro.

Ademais, depois de mais de uma década, as novas iniciativas de integração e cooperação regional não apresentaram resultados brilhantes. A UNASUL não conseguiu construir a chamada "nova arquitetura financeira" em torno do Banco do Sul. Embora alguns espaços como a IIRSA e o Conselho de Saúde da América do Sul tenham tido um sucesso moderado, outros como a proposta de integração energética fracassaram, sendo o melhor exemplo o projeto faraônico de um gasoduto do sul da Venezuela à Argentina. Por outro lado, a crise política na Venezuela evidenciou a ineficácia do bloco para lidar com governos de esquerda que violavam as regras democráticas.

A UNASUL nomeou em 2014 uma Comissão de Ministros das Relaçóes Exteriores com representantes da Colômbia, Equador e Brasil para mediar o diálogo político entre o governo e a oposiçãa venezuelana. A Comissão da UNASUL visitou Caracas e promoveu uma solução pacífica para a crise. $\mathrm{O}$ Secretário-Geral Ernesto Samper decidiu também participar ativamente da mediação. O diálogo político falhou porque a administração de Maduro não aceitou quase nenhuma das reivindicaçóes da oposição. Em particular, o pedido de libertação de todos os presos políticos é rejeitado e o líder opositor Leopoldo Lopez é condenado à prisão.

A fracassada mediação da UNASUL transformou a imagem do grupo regional tanto na Venezuela quanto em alguns países sul-americanos, como Colômbia e Paraguai. Havia a percepção de que a UNASUL atendia aos interesses do governo venezuelano. Isso ficou bem claro quando em fevereiro de 2014, em meio a manifestaçóes na Venezuela, os Ministros das Relaçóes Exteriores da UNASUL manifestaram seu apoio ao governo de Maduro e seu repúdio a qualquer tentativa de mudança política violenta no país. Na verdade, isso implicou um juiz de valor vis-à-vis as manifestaçóes populares na Venezuela, que realmente visavam uma solução para a crise política, econômica e institucional do país. 
Carlos Closa e Stefano Palestini Céspedes (2015) argumentam que o fracasso da UNASUL na Venezuela tem uma explicação clara. O mecanismo de mediação da UNASUL tinha um viés, foi criado e desenvolvido para proteger o governo (principalmente os de esquerda) que corriam o risco de ser derrubados ilegalmente. Foi o caso de Morales, Correa e Lugo. O mecanismo nunca foi aplicado a um governo eleito legítimo que tivesse decidido violar as regras e práticas democráticas, como acontecia na Venezuela. Além disso, a mediação era regulamentada pelos governos, mas a regra acabara sendo aplicada por um governo da UNASUL. Assim, os governos eram juízes e parte do conflito.

Por fim, se precisava a aprovaçáo do país envolvido na crise para que fosse aprovada uma mediação. Devido à natureza intergovernamental do processo decisório da UNASUL, o consenso de todos os membros do esquema regional era requerido. Portanto, Riggirozzi e Grugel afirmam que

[...] o fato de os países sul-americanos usarem a UNASUL para defender a democracia não é uma evidência - e não deve ser interpretada como implicando - que a UNASUL faça parte de um projeto de profunda democratização ou governança cidadá. A UNASUL está disposta a agir para impedir que governos eleitos sejam derrubados, mas não está pressionando por mecanismos para garantir a voz ou representação dos cidadãos - na verdade, tais medidas seriam consideradas como interferência indevida nos poderes dos estados-membros (RIGGIROZZI; GRUGEL, 2015, p. 796).

A crise na Venezuela evidenciou a deficiência da UNASUL para resolver a crise quando os governos são acusados e violar as regras da democracia. Mostra também que a UNASUL foi bloqueada, o controle dos governos nacionais sobre o processo decisório deu a eles a última palavra na busca de uma solução. Isso foi usado pelo governo mais radicalizado para impedir qualquer monitoramento sério de suas práticas democráticas (ou autoritárias).

No caso da ALBA, a queda do preço do petróleo limitou a capacidade da Venezuela de continuar financiando programas sociais e educacionais como mecanismo de liderança regional. A crise política, econômica e institucional venezuelana também influência no desenvolvimento da ALBA. Durante a era Chávez, as instituiçóes democráticas foram gradualmente enfraquecidas por meio de uma série de reformas legais que deram ao chavismo o controle das instituiçóes eleitorais e judiciais. No entanto, Chávez teve sucesso em se mostrar e a seu regime como democráticos, pois ganhou a maioria das eleiçóes e aceitou a existência de certa oposição política. Ele aceitou mesmo quando foi derrotado, 
como aconteceu em 2007, quando seu projeto de reforma constitucional foi rejeitado pela população. Como um regime híbrido, a democracia da Venezuela na era Chávez combinava elementos de democracia e autocracia (CORRALES; HIDALGO, 2013, 2017).

Esta situação foi modificada após a ascensão ao poder de Maduro em 2013. As características autoritárias do regime tornaram-se cada vez mais abertas. $\mathrm{O}$ regime não aceitou quando foi derrotado nas eleiçóes livres, como aconteceu em 2015, quando a oposição venceu as eleiçôes parlamentares e assumiu o controle da Assembleia Nacional. Embora a vitória da oposição tenha sido aceita formalmente por Maduro, imediatamente o regime desenvolveu uma estratégia para neutralizar a Assembleia usando o Supremo Tribunal de Justiça como instrumento. Posteriormente, em 2016, o poder eleitoral, controlado pelo chavismo, rejeitou a exigência de referendo revogatório estabelecido na constituição venezuelana. Em vez disso, Maduro convocou eleiçóes para estabelecer uma Assembleia Constituinte seguindo critérios não previstos na Constituição venezuelana. Quando a população manifestou nas ruas seu repúdio a essas violaçôes, o regime optou pela repressão e violaçóes dos direitos humanos, bem como pela perseguição aos líderes da oposição política. Um regime sem legitimação interna dificilmente pode pretender ter alguma liderança não somente na ALBA, mas no regionalismo latino-americano em geral.

No caso do "novo Mercosul", as políticas pós-liberais também tiveram limitaçôes. O progresso em temas sociais e produtivas foi menor do que o proposto. Embora tenha havido progresso em questóes como direitos humanos, em particular o resgate da memória histórica das atrocidades das ditaduras, ou uma maior participaçáo dos atores sociais, poucos avanços concretos e mensuráveis foram observados em projetos como o Plano Estratégico de Ação Social. Na área produtiva, o Programa de Integração Produtiva praticamente não pode mostrar resultados. E politicamente, o golpe no Paraguai teve duas consequências principais: por um lado, paralisou a ratificação do Protocolo de Ushuaia II, aprovado em 2011 para aprofundar a defesa da democracia, e por outro, permitiu a entrada irregular da Venezuela, que foi apenas o resultado final do tempestuoso processo de entrada deste país no bloco. E enquanto esses processos se enfraqueciam, a Aliança do Pacífico, embora com bom apoio da mídia internacional, era apresentada como um modelo de integração mais realista e bem-sucedido. 


\section{O fim do ciclo pós-hegemônico e o impasse do regionalismo}

A mudança política na Argentina com Mauricio em 2015 e o polêmico impeachment de Dilma Rousseff em maio de 2016, levou governos de centro-direita ao poder em dois países do Mercosul e da UNASUL. Isso foi o início do fim do ciclo pós-hegemônico. Os dois governos questionaram o rumo do Mercosul na era pós-hegemônica, abandonando sua dimensão comercial e suas relaçóes com o resto do mundo.

Esta crítica acontecia num momento em que projetos como o Acordo de Cooperação Transpacífico (TPP) e o Acordo Transatlântico de Comércio e Investimentos (TTIP) pareciam moldar a uma nova ordem comercial internacional. No caso da UNASUL, Argentina, Brasil, Paraguai, Chile, Peru e Colômbia questionaram a capacidade do bloco de resolver crises como a da Venezuela ou mesmo a impossibilidade de chegar a um consenso para nomear seu novo Secretário-Geral em 2017. Ernesto Samper devia cessar as suas funçóes em janeiro de 2017, num momento quando a Argentina exercia a Presidência Protempore na UNASUL. Macri propôs José Bordon, um conhecido diplomata argentino como novo Secretário-Geral, mas isso foi imediatamente rejeitado pela Venezuela. Como é necessário consenso para tomar decisóes na UNASUL, a nomeação de um novo Secretário-Geral foi suspensa. Isso teve um impacto profundo na imagem da UNASUL que foi percebida como um esquema paralisado. A rejeição da candidatura de Bordon teve implicaçóes regionais, pois em abril de 2018 seis membros da UNASUL (Argentina, Brasil, Colômbia, Chile, Paraguai e Peru), decidiram suspender sua participação nas reunióes das instituiçóes da UNASUL. Em agosto de 2018, o presidente Duque formalizou a então retirada colombiana da UNASUL. Seria depois acompanhado depois pelo Chile, Argentina, Brasil, Paraguai, Peru, Equador e Bolívia. Os governos conservadores acabaram substituindo a UNASUL pelo Foro para o Progresso e Desenvolvimento da América do Sul (PROSUL), uma iniciativa da Colômbia e Chile, formalizada em março de 2019.

A CELAC também ficou em segundo plano para os governos de centro-direita, principalmente após a tentativa fracassada do governo de Maduro de utilizá-la como espaço para discutir a crise em seu país. A ALBA também sofreu as consequências da virada conservadora, quando o Equador se retirou em 2017 e a Bolívia em 2019.

Embora os governos de centro-direita tenham sido capazes de reverter o ciclo pós-hegemônico, eles não conseguiram construir uma alternativa bem-sucedida. Salvo tentativas irrealistas de retomada do regionalismo aberto, em 
um contexto de nacionalismo econômico e protecionismo após o triunfo de Donald Trump nos Estados Unidos em 2016, os governos de centro-direita não apresentaram propostas inovadoras para relançar o regionalismo latino-americano. Alguns desses governos, Michel Temer ou Jair Bolsonaro, por exemplo, não parecem se interessar pelo assunto. E nenhum deles tentou ao menos fazer um esforço para resgatar algum aspecto positivo do ciclo anterior. Na verdade, é válido perguntar se a chegada de governos conservadores implicou um novo ciclo de hegemonia neoliberal e um retorno do regionalismo aberto (ou do que autores como James Baldwin (2011) qualificam de regionalismo do século 21), ou se estamos realmente num impasse desde 2015, sem que exista uma orientação clara para onde está indo o regionalismo e sem um plano para dar um novo impulso.

Vários fatos revelam esse impasse, mas o principal é que a agenda promovida pelos governos conservadores vai na direção oposta ao que as potências globais estão fazendo. Assim, por exemplo, Macri na Argentina ou Bolsonaro no Brasil compartilham uma visão de defensa do livre comércio e tem dado prioridade à assinatura de tratados com terceiros países ou blocos regionais. Macri, por exemplo, propôs acelerar a convergência entre o Mercosul e a Aliança do Pacífico e chegou a sugerir algum tipo de conexão com o TTP, apesar do caráter "atlântico" do Mercosul devido à sua localização geográfica. Também promoveu o relançamento e a conclusão do acordo de associação com a União Europeia (UE) e sugeriu mesmo o interesse em negociar um TLC com os Estados Unidos. Embora Temer tenha sido mais cauteloso em suas propostas, deu prioridade à reaproximação com a Aliança do Pacífico e negociaçóes com a UE. Bolsonaro tem uma posição mais radicalizada e favorável ao livre comércio e propôs a firma de acordo com Canadá, Singapura, Coreia do Sul a Associação Europeia do Livre Comércio (EFTA).

No entanto, essa ambiciosa agenda externa não foi replicada com uma agenda interna para resolver os problemas que o bloco tem na esfera comercial, como o acesso aos mercados da Argentina e do Brasil por parte do Paraguai e do Uruguai, ou a ineficácia do marco institucional regional. Nesse último aspecto, houve até um retrocesso, como a decisão de suspender a eleição direta dos membros do Parlamento do Mercosul, tomada em 2019.

Observa-se, então, uma agenda externa dinâmica e uma agenda interna pobre. É uma ilusão tentar relançar um bloco regional apenas a partir da agenda externa. A chegada ao poder de Jair Bolsonaro no Brasil complicou as coisas. Por um lado, o ministro da Fazenda, Paulo Guedes, declarou em 2018 que nem a Argentina nem o Mercosul eram importantes para o novo governo 
(Clarin em português, 30 de outubro de 2018³). Em 2019, Bolsonaro e alguns de seus porta-vozes interferiram na campanha eleitoral na Argentina, chegando a ameaçar que, se o candidato Alberto Fernández fosse eleito e quisesse impor medidas protecionistas a bloco, o Brasil se retiraria do Mercosul. Fernández também não fez muito para sossegar a situação ao denunciar a detenção do ex-presidente Lula de Silva como ilegal e ao visitá-lo em Curitiba, quando o ex-presidente estava preso. Além disso, o governo Bolsonaro tenta promover uma agenda de reformas internas no Mercosul, mas o faz com uma abordagem de liberalização comercial radical dentro do bloco e aprofundamento da agenda externa. Mario Abdo do Paraguai quanto Luis Lacalle Pou do Uruguai apoiam a Bolsonaro neste tema, mas é rejeitado pelo Fernández na Argentina, um país-chave do Mercosul.

$\mathrm{O}$ caso do Mercosul mostra que os governos conservadores não deram uma leitura adequada às mudanças ocorridas no sistema internacional. Tanto o regionalismo quanto o multilateralismo foram duramente golpeados pela ascensão de líderes nacionalistas no mundo desenvolvido. $\mathrm{O}$ caso emblemático é obviamente Donald Trump, cujas políticas expressam um questionamento da estratégia de promoção do regionalismo e da integração econômica de seus antecessores, evidenciada pela retirada do TPP, a renegociação do Tratado de Livre Comércio de América do Norte (NAFTA) e o Acordo Livre com a Coreia do Sul. Também o Brexit evidencia o momento de fragilidade do regionalismo internacional. Nesse contexto, não parece realista pretender uma nova forma de regionalismo aberto.

Um segundo caso é a substituição da UNASUL pelo PROSUL. Trata-se de uma proposta de Ivan Duque, da Colômbia, e Sebastian Piñera, do Chile, que convocam uma cúpula em março de 2019, da qual a Venezuela foi excluída. Pode-se argumentar que o PROSUL é uma proposta concreta dos governos de centro-direita, mas, se for, mostra uma desvalorização do regionalismo. Com todas as suas limitaçóes e erros (principalmente no manejo da crise venezuelana), a UNASUL foi um esquema que criou espaços de cooperação funcional, por exemplo, em saúde ou infraestrutura, que geraram resultados concretos. Podemos, por exemplo, relembrar o papel do Conselho de Saúde da América do Sul para enfrentar a crise do H1N1 em 2009.

A PROSUL carece do menor arcabouço institucional e, portanto, sua capacidade de reagir a uma crise como a pandemia Covid-19 é limitada. É um absurdo entender, a menos que a lógica de negar o passado seja a única guia de

\footnotetext{
3 Disponível em: https://www.clarin.com/clarin-em-portugues/brasil/futuro-ministro-da-fazenda-do-brasilmercosul-argentina-nao-sao-prioridade_0_Uhridlsbm.html. Acesso em: 9 jan. 2021.
} 
conduta, que se os governos conservadores fossem maioria na UNASUL e não aproveitariam a oportunidade para reformá-la e adaptá-la à sua visão regionalista. Suprimir a UNASUL e substituí-lo por uma entidade como a PROSUL, que ficou sem atividade até praticamente março de 2020, é mais uma evidência da falta de uma agenda regional clara por parte dos governos conservadores.

Também importa analisar a situação da Aliança do Pacífico, o bloco mostrado como modelo pelos governos conservadores. Na verdade, não seria sério falar de uma crise da Aliança, mas existem sinais preocupantes. Dentro da Aliança, em 2018 Andrés Manuel López Obrador, um severo crítico do neoliberalismo, foi eleito presidente do México, enquanto o Chile viveu semanas de protestos em outubro de 2019 que questionaram o modelo econômico vigente por décadas. Em outubro de 2020 os chilenos decidiram convocar uma Assembleia Constituinte para elaborar uma nova Constituição. Isto evidencia certo grau de instabilidade política no bloco. Por outro lado, o cenário de convergência com o Mercosul se complica com a ascensão de Alberto Fernández ao poder na Argentina em 2019 e com a presidência de Jair Bolsonaro no Brasil, líder que parece dar pouca importância à integração regional. Além disso, oito anos já é um tempo razoável para avaliar o desenvolvimento da Aliança do Pacífico. É realmente um projeto tão bem-sucedido e inovador quanto é descrito? Quanto progresso foi feito na integração profunda? A interdependência regional aumentou? A Aliança ainda é vista como modelo para a região?

Muitas das perguntas acima já estáo começando a ser respondidas. Alguns especialistas (VIEIRA, 2015; MARCHINI, 2019) questionam o conceito de integração profunda. Vieira, por exemplo, debate respeito à profundidade da integração, uma vez que se pretende "[...] realizar uma construção eminentemente pragmática que incorpore no mesmo cabaz vários tipos de compromissos econômicos, comerciais, políticos, sociais e de cooperação, sem traçar um mínimo sua conceitualização em seus objetivos" (VIEIRA, 2015, p. 64). Marchini considera que "integração profunda" é um conceito equivocado pelos diversos usos que dela tem sido feito (MARCHINI, 2019).

O baixo nível de comércio intra-Aliança também tem sido discutido. Já se passaram mais de sete anos desde a assinatura do acordo-quadro e a intensidade do comércio regional continua muito baixa. Era o que acontecia já em 2012, apesar de os países da Aliança terem assinado acordos bilaterais de livre comércio, condição necessária para serem membros do bloco. Assim, em 2015, o comércio intra-Aliança representou apenas 3,2\% de todas as exportaçóes dos países-membros (CRACAU; DURAN LIMA, 2019). Uma investigação de Albio Márquez Rangel (2015) mostra resultados semelhantes, ou seja, uma baixa troca 
intrarregional que é explicada pela baixa complementaridade econômica. Por isso, o autor afirma que

[...] não só um audacioso programa de liberalização comercial é suficiente para impulsionar o comércio intrarregional na AP, mas também precisa a implementaçáo de políticas conjuntas de diversificaçáo econômica que visem elevar a qualidade da cesta de produtos de exportaçáo de cada um de seus países-membros (MÁRQUEZ RANGEL, 2015, p. 80).

Por essas razóes, especialistas como Eric Tremolada $(2014,2015)$ discutem a originalidade da Aliança do Pacífico como um modelo inovador de integração, uma vez que é apenas uma zona de livre comércio à qual se adicionam experiências relativamente novas de coordenação das bolsas valores e programas educacionais de intercâmbio. Sua institucionalidade também é questionada por ser basicamente intergovernamental (VIEIRA, 2019).

Em resumo, antes da chegada do Covid-19, o regionalismo latino-americano experimentava um impasse, um período de confusão no qual os governos conservadores tinham destruído uma parte importante do legado da era pós-hegemônica, enfraquecendo as dimensôes políticas, sociais e produtivas, mas sem ter um projeto para sua substituição. A única estratégia era a firma de acordos de livre comércio com o resto do mundo.

\section{A chegada do Covid-19}

A Covid-19 chega à América Latina neste contexto. As respostas regionais à pandemia têm sido diversas. Em esquemas que promoveram objetivos além do comércio ou nos quais o regionalismo é percebido como um processo multidimensional, as ações comuns em relação à Covid-19 têm sido mais tangíveis. São os casos do SICA e da CARICOM, nos quais existiam instituiçóes regionais de saúde antes da pandemia. Apesar de ser um processo atualmente dividido ideologicamente, o Mercosul também tinha instituiçôes regionais dedicadas as questóes sociais. Mas o viés comercial que tem o bloco desde 2015 tem obstaculizado a aprovação de decisóes importantes para abordar a crise, apenas se aprovaram US \$ 16 milhóes para o projeto regional "Pesquisa, Educação e Biotecnologias aplicadas à Saúde”, esses recursos são para o avanço da pesquisa sobre Covid-19.

\footnotetext{
4 Disponível em: https://www.mercosur.int/esfuerzo-regional-contra-la-pandemia-el-mercosur-aprobo-un-fondode-emergencia-de-us16-millones-que-seran-destinados-en-su-totalidad-al-combate-coordinado-contra-el-covid-19/. Acesso em: 8 jan. 2021.
} 
Por outro lado, aquelas iniciativas nas quais o regionalismo está centrado no livre comércio e nas questóes econômicas não têm participado na solução da crise, por exemplo, a Aliança do Pacífico. Existe um caso ainda pior, a CAN que tem uma agência regional de saúde, o Acordo Hipólito Unanue, mas incapaz de impulsionar políticas públicas regionais vis-à-vis a pandemia.

O caso centro-americano é bem interessante. Os Chefes de Estado e de Governo do SICA realizaram uma Cúpula Virtual em 12 de março 2020 e decidiram desenvolver um Plano de Contingência Regional para dar resposta à Covid-19. O Plano visa complementar os esforços nacionais na prevenção, contenção e tratamento da Covid-19. Aprovado em 26 de março, o Plano incluiu um fundo de emergência de US \$ 8 milhóes (um milhão para cada membro do SICA) com recursos do Banco Centro-Americano de Integração Econômica. O Plano é composto por 4 eixos: saúde e gestão da saúde; comércio e finanças; comunicação estratégica e gestão da cooperação internacional. Foi também decidido que o Conselho Centro-Americano de Ministros da Saúde (COMISCA) adquirirá medicamentos e material médico, em concreto mais de 180.000 kits de teste Covid-19. Um Fundo de Emergência de US \$ 1,9 bilhão também foi aprovado para administrar a crise econômica gerada pela pandemia 5 .

Infelizmente, o caso sul-americano é muito diferente. O Conselho SulAmericano de Saúde da UNASUL teve um papel crucial durante a crise do H1N1 em 2009, mas os governos de centro-direita eliminaram de fato o bloco em 2019 e estabeleceram o PROSUL. Em meio à crise, uma cúpula virtual do PROSUL foi realizada em 17 de março de 2020 para discutir açóes para controlar a pandemia. Em outra reunião realizada em 7 de abril, os líderes do PROSUL concordaram em realizar compras comuns de insumos médicos. No entanto, o PROSUL não tem instituições permanentes para implementar essas decisóes, que no caso da UNASUL correspondia ao Conselho Sul-Americano de Saúde.

A CELAC, instituição cataléptica por vários anos, foi reativada durante a presidência pro-tempore de México. Uma Reunião para Monitoramento da Covid-19 foi convocada em 30 de janeiro de 2020; uma segunda reunião foi realizada em 19 de fevereiro. A CELAC participou no dia 4 de maio de uma Cúpula organizada pela União Europeia (UE) para promover a Iniciativa de Resposta Global para gerenciar a crise Covid-19.

Assim, a crise gerada pela Covid-19 mostra que diversas açóes sub-regionais têm sido fomentadas e tem ocorrido, até mesmo, um esforço para promover uma resposta regional latino-americana no quadro da CELAC. Apesar de ter

Disponível em: https://www.sica.int/coronavirus/plan. Acesso em: 8 jan. 2021. 
sido criticado por sua atual estagnação, os esquemas regionais latino-americanos têm tentado dar respostas à crise. Contudo, as respostas têm sido diferentes, e na verdade, o regionalismo sul-americano tem sido reprovado. Uma conclusáo pode ser inferida das diversas açôes até agora observadas: o modelo de regionalismo importa.

Assim, as respostas à pandemia Covid-19 mostram que entender o regionalismo como um fenômeno multidimensional e não apenas comercial e econômico pode fazer a diferença na hora de participar na resolução de crises que não são mais estritamente nacionais. Mas uma visão multidimensional sem açóes concretas equivale a nada. A CAN é um processo multidimensional e a falta de ação do acordo Hipólito Unanue é surpreendente e evidencia a crise do processo andino. O PROSUL tentou desempenhar o papel que a desaparecida UNASUL exerceu na crise do H1N1 em 2008. No entanto, a UNASUL tinha uma estrutura institucional que o PROSUL não tem. Para outros esquemas como a Aliança do Pacífico, a Covid-19 era apenas um problema que poderia afetar o comércio.

O Mercosul é outro caso difícil de explicar. É verdade que existe um Instituto Social do MERCOSUL e a saúde é um dos Eixos do Plano Estratégico de Ação Social aprovado em 2011. Em consequência, seria de se esperar uma resposta regional coordenada ainda mais forte que aquela do SICA, porque os países do MERCOSUL têm mais recursos financeiros. Esse não foi o caso. Os recursos aprovados têm sido limitados, em grande parte devido ao enfraquecimento das instituiçóes e projetos sociais do Mercosul desde a chegada de governos conservadores.

Além disso, a falta de políticas nacionais rigorosas no Brasil para gerenciar a pandemia tem sido criticada pelos parceiros do MERCOSUL. Os governos da Argentina e do Uruguai, onde o vírus tem sido relativamente controlado, manifestaram preocupação com o crescente número de casos no Brasil. Devemos lembrar que o presidente Jair Bolsonaro descreveu a Covid-19 como uma "gripezinha”. Pode-se argumentar que as diferenças ideológicas explicam as críticas do presidente argentino Alberto Fernández ao Brasil, mas isso parece incorreto. $\mathrm{O}$ presidente Alberto Lacalle no Uruguai e até Mario Benítez no Paraguai, ambos de partidos conservadores, também se opuseram à estratégia brasileira e denunciaram o risco de propagação regional do vírus a partir do Brasil.

Por fim, pode-se argumentar que os recursos aprovados pelas instituiçóes regionais são limitados e os planos estão longe de ser uma política pública regional para fazer frente à pandemia. A crítica pode ser válida, mas mesmo a UE, o processo regional mais avançado, náo conseguiu desenhar uma política comum 
para a pandemia. O certo é que, no mundo globalizado, o regionalismo precisa de instituiçóes fortes para lidar com questóes sociais, como a saúde.

\section{Conclusões}

O regionalismo latino-americano vive um impasse desde 2015. Os governos conservadores foram bem-sucedidos em destruir o legado do período pós-hegemônico, mas não conseguiram construir um modelo alternativo para superar as limitaçóes dos processos regionais. Aparentemente a única estratégia dos governos conservadores era a negociação de acordos comerciais com países e blocos do norte desenvolvido, num contexto internacional náo muito favorável para o livre comércio. Contudo, as falhas estruturais do regionalismo não foram atendidas, como o baixo nível, o comércio inter-regional, os problemas institucionais ou o incumprimento das metas nas áreas da integraçáo produtiva e social. A crise da Covid-19 confirmou as fraquezas do regionalismo, especialmente, na América do Sul. As divisóes políticas e diferenças ideológicas entre importantes países da região e a falta de pragmatismo, não permite visualizar que a superação de impasse atual aconteça no curto prazo.

\section{REFERÊNCIAS}

BALDWIN, R. 21st century regionalism: Filling the gap between 21st century trade and 20th century trade rules. WTO Working Papers, Genebra, n. 2011/08, 2011. Disponível em: https://doi. org/10.30875/c67646a3-en. Acesso em: 8 jan. 2021.

BENZI, D. ALBA-TCP: Anatomía de una integración que no fue. Quito: Ediciones Imago Mundi, 2017.

BENZI, D.; NAREA, M. El regionalismo suramericano después del "giro a la izquierda”: Balance y perspectivas de la UNASUL. En: BRICEÑO RUIZ, J. et al. (coord.). La integración latinoamericana en debate: Incertidumbre, formatos institucionales fragmentados y caminos alternativos latentes. Buenos Aires: Teseo, 2019. p.47-68.

BRICEÑO RUIZ, J. Hegemonía, poshegemonía, neoliberalismo y posliberalismo en los debates sobre el regionalismo en América Latina. En: ARDILA, M. (ed.). ¿Nuevo multilateralismo en América Latina?: Concepciones y actores en pugna. Bogotá: Universidad Externado de Colombia, 2016. p. 23-66. 
BRICEÑO RUIZ, J. Del regionalismo estratégico al regionalismo social y productivo: Las transformaciones del modelo de integración en el MERCOSUR. En: BRICEÑO RUIZ, J. (ed.). Mercosur y las complejidades de la integración regional. Buenos Aires: Teseo, 2011. p. 121-164.

CLOSA, C.; PALESTINI CÉSPEDES, S. Between democratic protection and selfdefense: The case of UNASUL and Venezuela. RSCAS Working Papers, Fiesole, n. 2015/93, 2015. Disponível em: http://hdl.handle.net/1814/38064. Acesso em: 8 jan. 2021.

CORRALES, J.; HIDALGO, M. The Quality of the Venezuelan Demoracy under Hugo Chavez (1999-2013). Partecipazione e conflitto, Lecce, Itália, v.10, n.1, p.89-118, 2017.

CORRALES, J.; HIDALGO, M. El régimen híbrido de Hugo Chávez en transición (2009-2013). Desafíos, Bogotá, Colombia, v.25, n.1, p.45-84, 2013. Disponível em: https://revistas.urosario.edu.co/index.php/desafios/article/view/2577/2166. Acesso em: 8 jan. 2021.

CRACAU, D.; DURÁN LIMA, J. E. Trade and Investment Relations in the Pacific Alliance: Recent Developments and Future Trends. In: SAUVÉ, P.; LAZO, R. P.; ALVAREZ ZARATE, J.-M. (ed.). The Pacific Alliance in a World of Preferential Trade Agreements. Dordrecht: Springer, 2019. p. 29-64.

FERNÁNDEZ GUILLÉN, O. E. El regionalismo post-hegemónico en el marco del 'nuevo MERCOSUR'. Cuadernos sobre Relaciones Internacionales, Regionalismo y Desarrollo, Mérida, México, v.12, n.23, p.245-286, 2017.

GRATIUS, S.; PUENTE, J. M. ¿ Fin del proyecto alternativo ALBA?: Una perspectiva política y económica. Revista de Estudios Políticos, Madrid, n.180, p.229-252, 2018. Disponível em: https://doi.org/10.18042/cepc/rep.180.08. Acesso em: 8 jan. 2021.

MARCHINI, G. La Alianza del Pacífico a ocho ańos de su creación: Balance crítico y perspectivas. Anuario Latinoamericano: Ciencias Políticas y Relaciones Internacionales, Lublin, Polonia, v.7, p.75-109, 2019. Disponível em: http://dx.doi. org/10.17951/al.2019.7.75-109. Acesso em: 8 jan. 2021.

MARQUÉZ RANGEL, A. Desafíos a enfrentar por el comercio intrarregional en la Alianza del Pacífico. Aldea Mundo, Táchira, Venezuela, v.20, n.40, p.71-84, 2015.

MIJARES, V. M.; NOLTE, D. Regionalismo posthegemónico en crisis: ¿por qué la UNASUL se desintegra?. Foreign Affairs: Latinoamérica, Ciudad de México, v.18, n.3, p.105-112, 2018. 
MOLCHANOV, M. A.; MOLCHANOVA, V. Regionalist Projects in Eurasia: Toward the Post-hegemonic Model of Regional Integration. In: KFG CONFERENCE, 2010, Berlin. Diffusion Of Regional Integration, Berlin, dec. 2010. p.1-25.

RAPOPORT, M.; MUSACCHIO, A. El Mercosur y su encrucijada: entre la disolución y un replanteó radical. Ecuador Debate, Quito, n.68, p.7-18, 2006.

RIGGIROZZI, P.; GRUGEL, J. Regional governance and legitimacy in South America: the meaning of UNASUL. International Affairs, London, v.91, n.4, p.781-797, 2015.

RIGGIROZZI, P.; TUSSIE, D. The Rise of Post-Hegemonic Regionalism in Latin America. En: RIGGIROZZI, P.; TUSSIE, D. (ed.). The Rise of Post-Hegemonic Regionalism. Springer: Dordrecht, 2012. p. 1-16.

ROJAS ARAVENA, F. La Celac y la integración latinoamericana y caribeña Principales claves y desafíos. Nueva Sociedad, Buenos Aires, n.240, p.16-27, 2012.

SEGOVIA, D. Latin America and the Caribbean: Between the OAS and CELAC. European Review of Latin American and Caribbean Studies, Amsterdam, n.95, p.97-107, 2013.

SVAMPA, M. Neoextractivismo, lógicas del desarollo y conceptos en disputa en América Latina: 2000-2016. En: DE LA FUENTE, M.; RICALDI ARÉVALO, T.; SALDOMANDO, A. (ed.). Lógicas de desarrollo extractivisimo y cambio climático. Cochabamba: Universidad Mayor de San Simón, Centro de Estudios Superiores Universitarios, 2017. p. 15-46.

SVAMPA, M. Consenso de los commodities, giro ecoterritorial y pensamiento crítico en América Latina. OSAL, Buenos Aires, v.13, n.32, p.15-38, 2012.

TELÒ, M. The European Union, Regionalism, and World Order: Five Scenarios. Fédéralisme Régionalisme, Liège, v.11, n.2, p.1-13, 2011.

TREMOLADA, E. The Pacific Alliance: Much Ado about Nothing. Thammasat Journal of History, Lund, Suécia, v.2, n.2, p.97-243, 2015.

TREMOLADA, E. La integración de la Alianza del Pacífico. En: BUELVAS, E. P.; GEHRING, H. (ed.). Alianza del Pacífico: mitos y realidades. Cali: Editorial Universidad Santiago de Cali; Fundación Konrad Adenauer Stiftung, 2014. p. $145-172$.

VÄYRYNEN, R. Post-hegemonic and Post-socialist Regionalism: a Comparison of East Asia and Central Europe. Notre Dame: Joan B. Kroc Institute for International Peace Studies, 1997. 
VIEIRA, E. Integración de América Latina desde soberanías nacionales o en soberanía compartida. In: BRICEÑO RUIZ, J.; VIEIRA POSADA, E. (ed.). Repensar la integración en América Latina: Los casos del Mercosur y la Alianza del Pacífico. Bogotá: Universidad Cooperativa de Colombia, 2019.

VIEIRA, E. La Alianza del Pacífico: ¿integración profunda hasta qué grado?. In: RODRÍGUEZ ARANDA, I.; VIEIRA POSADA, E. (ed.). Perspectivas y oportunidades de la Alianza del Pacífico. Bogotá: Editorial CESA, CEGLI, 2015. p. 63-102.

Recebido em: 12 de setembro de 2020

Aprovado em: 05 de outubro de 2020 